\title{
In Memory of Nikolai Nikolaevich Shipkov (1929-2008)
}

DOI: $10.3103 / \mathrm{S} 0361521909020128$

Nikolai Nikolaevich Shipkov passed away at the age of 79 after an extended illness. He was an eminent scientist in the field of chemistry and technology of carbon materials, a long-term member of editorial board of our journal, a professor, and a Doctor of Engineering.

In 1953, Shipkov graduated from the Moscow Power Engineering Institute and for 10 years worked at the Krzhizhanovsky Power Engineering Institute of the USSR Academy of Sciences. Thereupon, he worked for more than 40 years at the Research Institute of Structural Graphite Materials (FGUP NIIgrafit) in the positions of section head, laboratory head, and processing department head. In 1971, Shipkov received his Doctor of Engineering degree, and in 1974 he became a professor.

Wholeheartedly devoting his own talent and erudition to scientific and organizational activities, Shipkov made an incomparable contribution to the advancement of carbon science and to the commercial production of carbon materials.

In 1974, he made a scientific discovery, in which a theretofore unknown effect was found experimentally: the rapid evaporation of carbon from liquid metal carbide and carbide-carbon eutectics in contact with a solid phase. This allowed him to establish the mechanism of the geochemical origin of natural graphite and diamond and to solve a number of problems on the production of synthetic diamonds in the presence of transition metals. Based on this discovery, methods for the production of a new class of unique construction materials (recrystallized graphites) were developed and commercialized.

Shipkov paid a great deal of attention to developing specific raw materials to obtain tailored graphites. The scientific principles for producing specific carbon materials to synthesize diamonds were created under his direction; their commercial manufacture was subsequently developed. By thermomechanical treatment of pyrolytic graphite, graphite monochromators for X-ray and neutron radiation were obtained for the first time in Russia. They considerably increased the accuracy of $\mathrm{X}$-ray and neutron diffraction analysis.

Based on his findings, Shipkov authored or coauthored some 400 publications, including 5 monographs, 120 inventor's certificates, and 15 patents.

Shipkov devoted much effort to teaching activity (as a professor at the Mendeleev University of Chemistry and Technology), together with scientific and organizational work. He was a member of the editorial boards of the journals Khimiya Tverdogo Topliva (Solid Fuel Chemistry) and Tsvetnye Metally (Nonferrous Metals), as well as a member of a number of dissertation committees and the expert councils of the Higher Certification Commission.

Under his direction, 30 candidate and 12 doctoral dissertations were defended.

Shipkov was given the rank of Honored Worker of Science and Engineering of the Russian Federation. He was elected a full member of the Russian Academy of Natural Sciences.

Shipkov was decorated with the Medal for Laborious Valor, the Medal for Valorous Labor, and the Badge of Honor. Shipkov won universal recognition and respect due to his energy, solidity of purpose, exactingness to himself and his subordinates, high responsibility toward assigned tasks, and professional knowledge.

The editorial board deeply mourns his untimely death and cordially sympathizes with his relatives, friends, and colleagues. 